International Journal of Applied Dental Sciences 2021; 7(1): 198-202

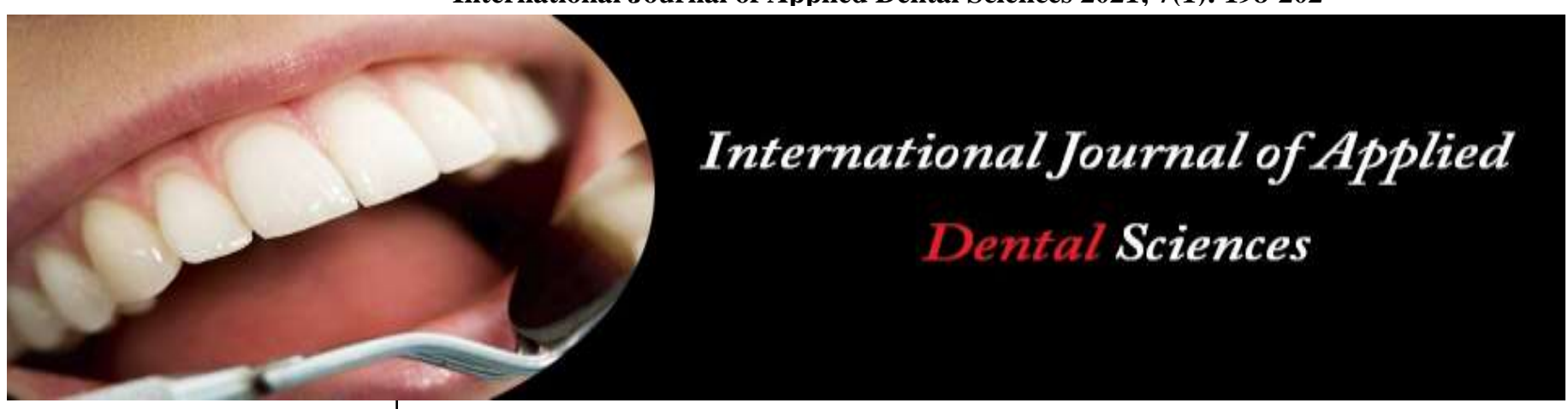

ISSN Print: 2394-7489

ISSN Online: 2394-7497

IJADS 2021; 7(1): 198-202

(C) 2021 IJADS

www.oraljournal.com

Received: 22-11-2020

Accepted: 28-12-2020

Dr. Apoorva R Jagtap

Part II MDS, Department of

Conservative Dentistry and

Endodontics, MGV's K.B.H.

Dental College and Hospital,

Nashik, Maharashtra, India

Dr. Gayatri B Aher

Reader, Department of

Conservative Dentistry and

Endodontics, MGV's K.B.H.

Dental College and Hospital,

Nashik, Maharashtra, India

Dr. Meenal N Gulve

Head of Department,

Department of Conservative

Dentistry and Endodontics,

MGV's K.B.H. Dental College

and Hospital, Nashik,

Maharashtra, India

Dr. Swapnil J Kolhe

Professor, Department of

Conservative Dentistry and

Endodontics, MGV's K.B.H

Dental College and Hospital,

Nashik, Maharashtra, India

Corresponding Author: Dr. Apoorva R Jagtap Part II MDS, Department of Conservative Dentistry and Endodontics, MGV's K.B.H. Dental College and Hospital, Nashik, Maharashtra, India

\section{Biomimetic restoration of posterior teeth using stamp technique: A case series}

\section{Dr. Apoorva R Jagtap, Dr. Gayatri B Aher, Dr. Meenal N Gulve and Dr. Swapnil J Kolhe}

DOI: $\underline{\text { https://doi.org/10.22271/oral.2021.v7.i1c.1136 }}$

\section{Abstract}

Accurate occlusal topography of posterior composite restorations is of utmost importance for proper functioning of stomatognathic system. Large posterior composite restorations can be time-consuming as well as is a skill-oriented process. Minor discrepancies in these restorations can cause long term craniomandibular disturbances. To overcome this and related problems of posterior composite restoration "Stamp Technique" was introduced. This technique has easy-to-follow procedures and helps to obtain precise tooth-filling with functional occlusion in teeth having intact occlusal surfaces and can be practiced by dentist in their busy practice. This article aims to demonstrate and discuss the use of this technique in different posterior teeth of all quadrants.

Keywords: Composite restorations, occlusal topography, stamp technique

\section{Introduction}

Traditionally teeth were restored with amalgam and cast-gold restorations which needed extensive cavity preparation and macro-retention features which are barely esthetic in appearance. With increasing public demand for esthetic restorations and the advent of adhesive cavity designs, composite resins are gaining popularity as posterior restorative materials ${ }^{[1]}$. Direct composite resin are widely used in dentistry. However, there are still some difficulties regarding handling of composite material, especially in large restorations. The reconstruction of a functional and individual occlusion is difficult to achieve with direct application techniques ${ }^{[2]}$. Furthermore, rebuilding tooth morphology free-hand in the attempt to achieve functional occlusion is time-consuming process ${ }^{[3]}$. The occlusal surface of the tooth is most susceptible to dental caries due to its complex morphology, which favours plaque accumulation and demineralization of tooth structure ${ }^{[4]}$. In posterior teeth, primary caries lesions may present an intact occlusal morphology despite of the caries exceeds the dentinoenamel junction in terms of depth. For these cases, the literature describes a restoration technique using an occlusal stamp that allows to mimic the original tooth morphology by using the existing clinical condition before the necessary destruction of tooth surface, reducing the time required for the removal of excess and polishing of restorations ${ }^{[5]}$. This technique is suitable in cases where the caries is evident during the clinical examination or routine radiographic examination of teeth with intact marginal ridges and ideal occlusal anatomy ${ }^{[6]}$.

To obtain ideal occlusal topography and good finishing in less time this study demonstrates four cases for restoration of posterior teeth of both maxillary and mandibular arch using Occlusal Stamp Technique.

\section{Case Report}

Case 1

A year old patient presented to dental clinic with the chief complain of mild sensitivity and decay in upper left back region of jaw. Oral examination revealed pit and fissure caries with 26 [figure 1a]. The extent of caries were detected on intraoral periapical radiograph. There was no marginal ridge involvement seen. After thorough examination and considering related factors it was decided to be restored with the help of occlusal stamp technique. 
Tooth was isolated with rubber dam and separating agent was applied to the occlusal surface. Then gingidam [Pola Office, SDI, Victoria, South-east Australia] was placed over the occlusal surface of 26. Microbrush head was then inserted into it and cured \{[figure 1b]. Stamp was obtained [figure 1c]. After caries excavation [figure 1d] cavity was etched with $37 \%$ phosphoric acid [Tetric N Etch Ivoclar Vivadent, Zurich, Switzerland] [figure 1e]. Then bonding agent [Tetric N Bond, Ivoclar Vivadent, Zurich, Switzerland] was applied and cured following composite placement [A2 shade Tetric N ceram, Ivoclar Vivadent, Zurich, Switzerland] 1mm short of occlusal surface[figure 1f]. Flowable composite [Ivoclar Vivadent, Zurich, Switzerland] was placed and teflon sheet was placed [figure 1g]. Stamp obtained was pressed against the teflon sheet and cured [figure $1 \mathrm{~h}$ ]. Teflon sheet was then removed and final finishing and polishing was done[figure 1i]. High points were checked with the articluating paper.

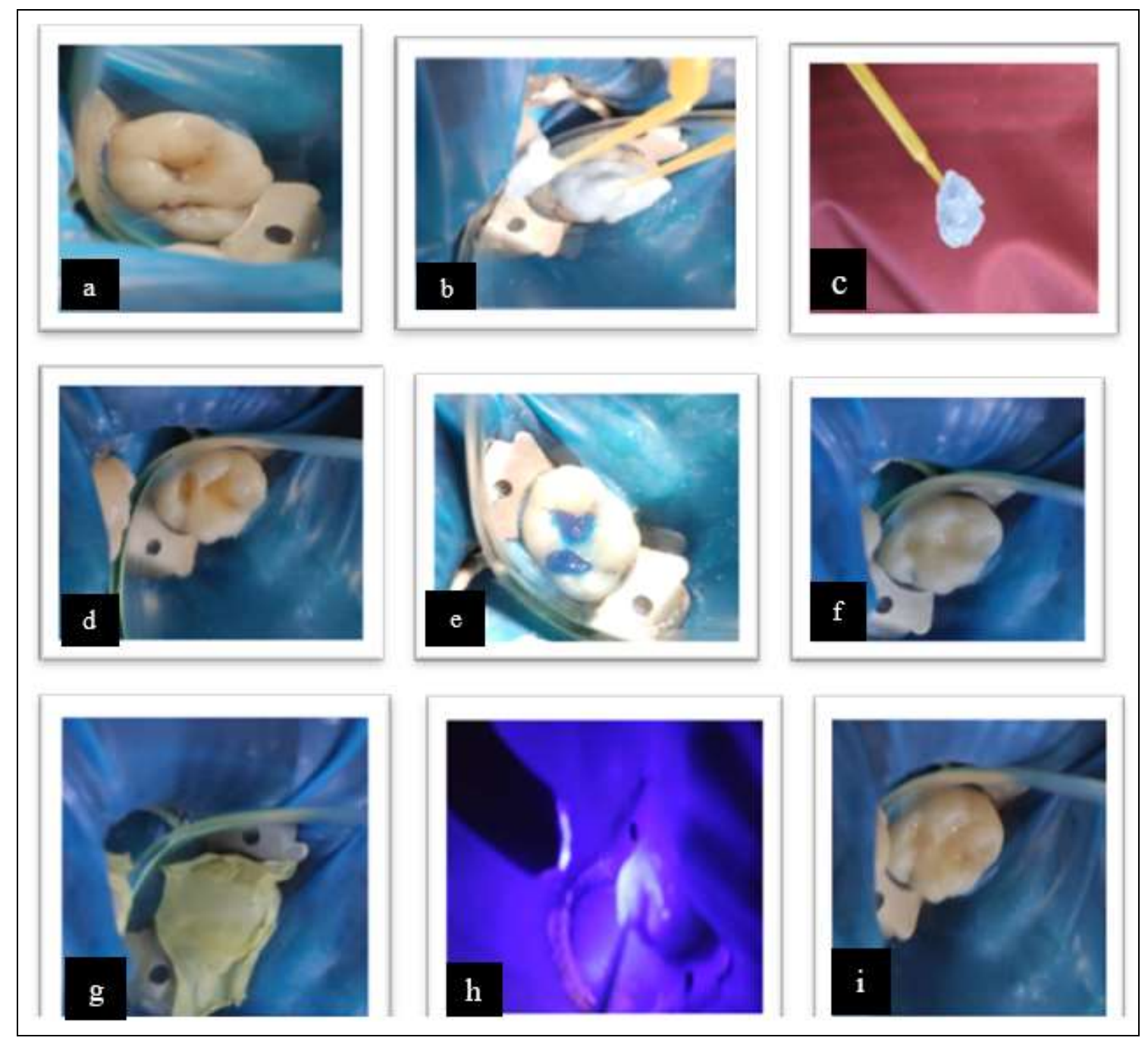

Fig 1: (a) Pre-operative image of 26. (b) micro brush inserted into gingidam applied to the tooth and cured(c) Stamp obtained(d) Cavity preparation (e) Etching of the cavity(f) Bonding agent applied and cured followed by composite placement (g) Flowable composite applied and Teflon sheet placement(h) Stamp placed over teflon sheet and cured (i) Final restoration after finishing and polishing

\section{Case 2}

A 25 year female reported to the clinic with the complain of sensitivity in lower left back region of jaw. Oral examination revealed class I caries with 35 [figure 2a]. Marginal involvement of caries was not seen in intraoral periapical radiographs. After thorough examination and deliberation it was decided to be restored with stamp technique.

After tooth isolation, all the steps were followed as per case one. [figure 2a-i]

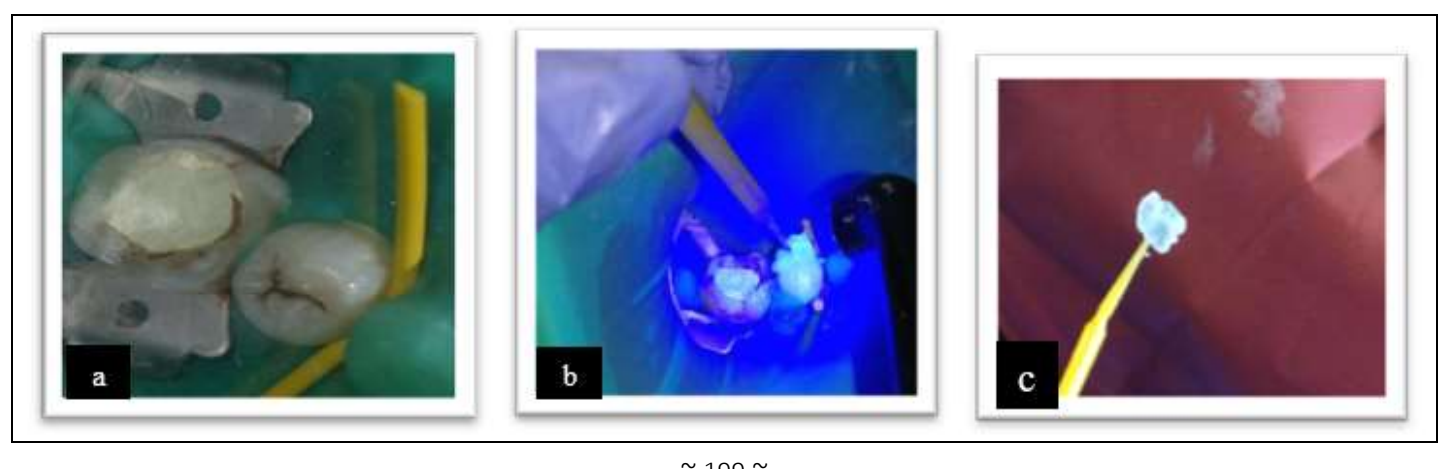




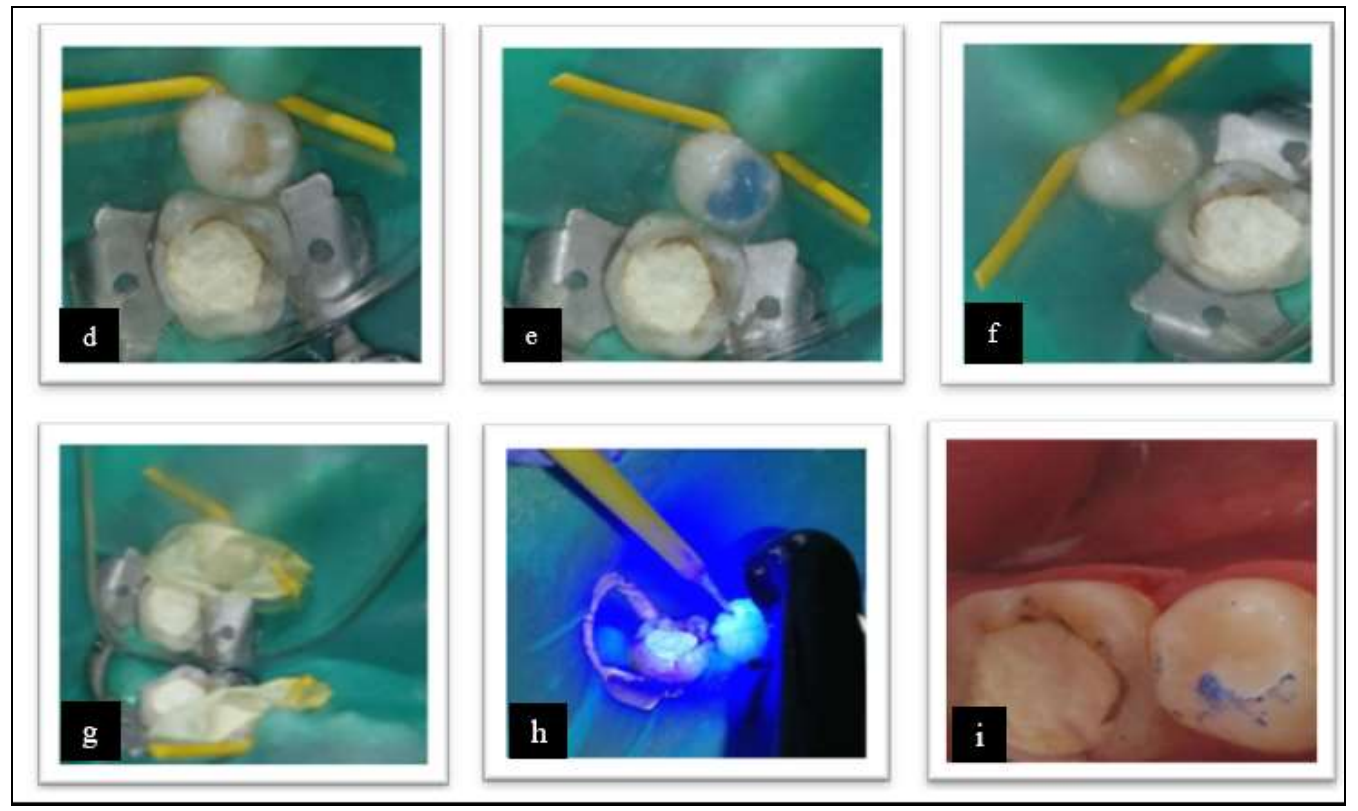

Fig 2: (a) Pre-operative image of 35 (b) microbrush inserted into gingidam applied to the tooth and cured (c) Stamp obtained (d) Cavity prepration (e) Etching of the cavity (f) Bonding agent applied and cured followed by composite placement (g) Flowable composite applied and Teflon sheet placement (h) Stamp placed over teflon sheet and cured (i) Final restoration after finishing and polishing.

\section{Case 3}

A 23 year old male reported to clinic complaining of discolouration in lower left back region of jaw. Oral examination revealed pit and fissure caries with 36 [figure 3a]. Intraoral periapical radiograph showed no marginal ridge involvement. After thorough examination and considering all the factors it was decided to be restored using occlusal stamp technique.

After tooth isolation, all the steps were follwed as per case one. [figure 3a-i]

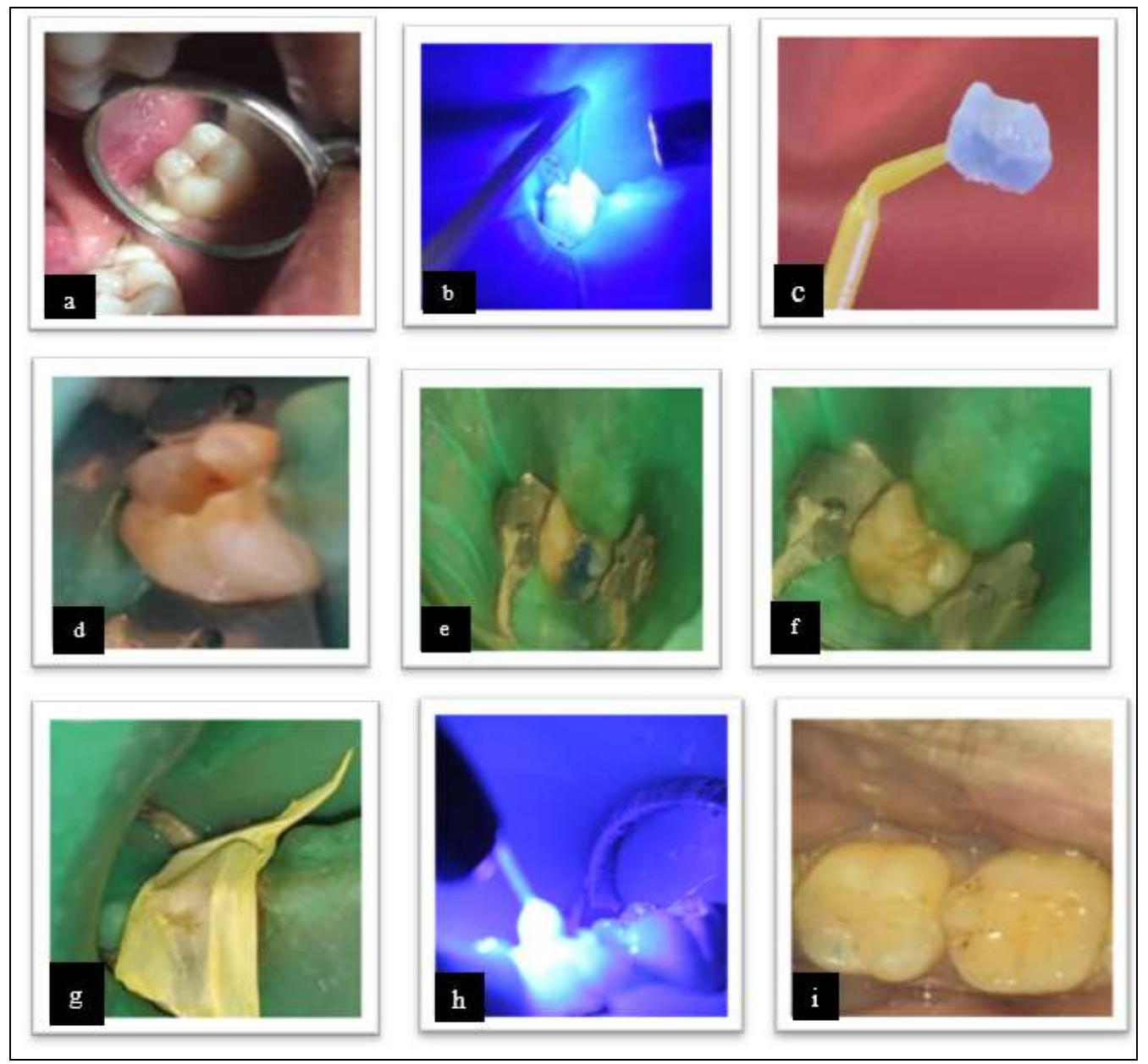

Fig 3: (a) Pre-operative image of 36. (b) microbrush inserted into gingidam applied to the tooth and cured(c) Stamp obtained(d) Cavity prepration done(e) Etching of the cavity done (f) Bonding agent applied and cured followed by composite placement(g) Flowable composite applied and Teflon sheet placement (h) Stamp placed over teflon sheet and cured (i) Final restoration after finishing and polishing. 


\section{Case 4}

A 18 year old female reported to clinic with the complain of sensitivity and discolouration in lower right back region of tooth. On clinical examination pit and fissure caries were seen with 46 [figure 4a]. Intraoral periapical radiograp were taken to confirm absence of marginal ridge involvement. After considering all the fcators it was decided to restore the tooth using stamp technqiue.

After tooth isolation, all the steps were follwed as per case one. [figure 4a-i]

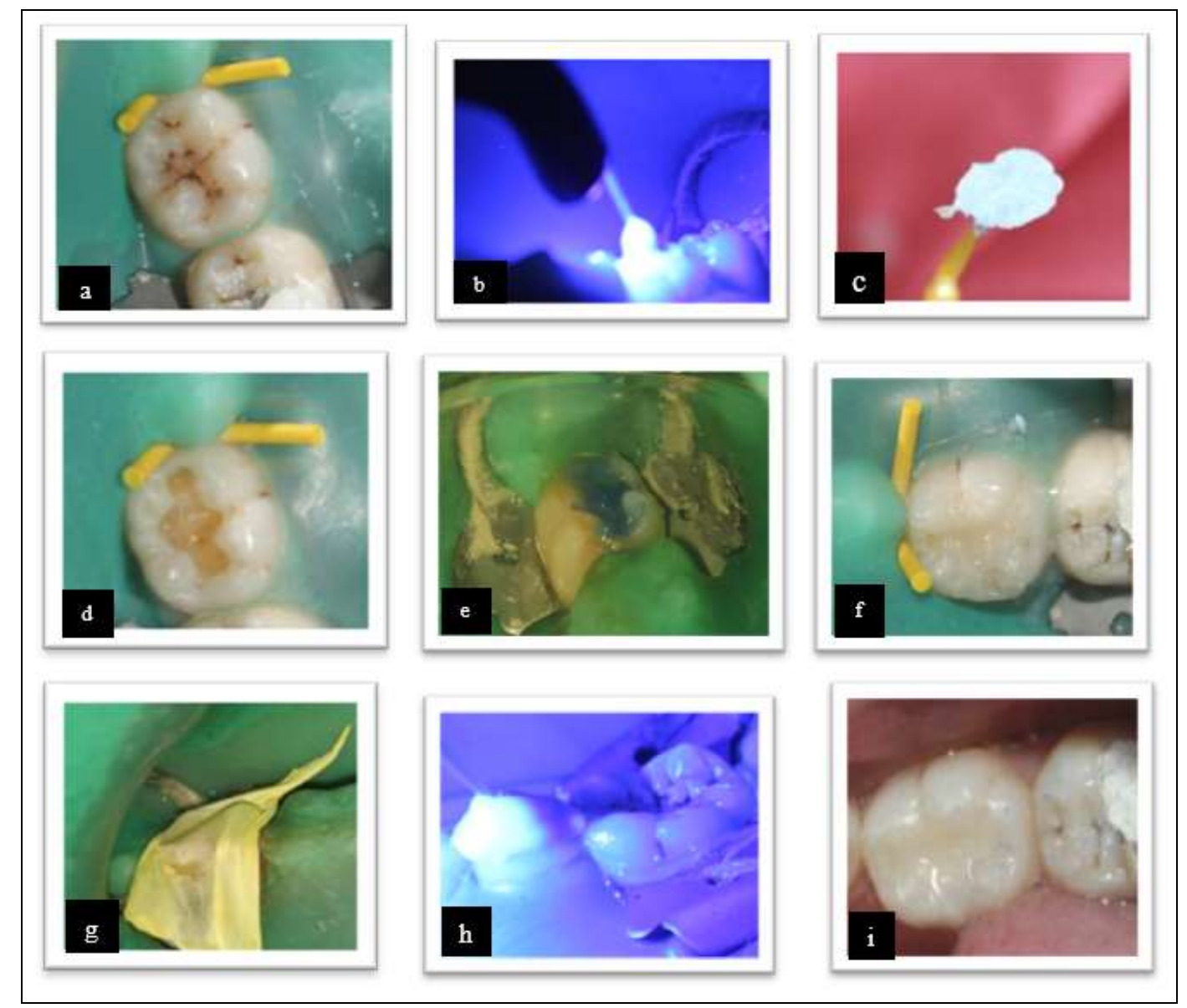

Fig 4: (a) Pre-operative image of 47(b) microbrush inserted into gingidam applied to the tooth and cured(c) Stamp obtained(d) Cavity prepration done(e) Etching of the cavity done (f) Bonding agent applied and cured followed by composite placement(g) Flowable composite applied and Teflon sheet placement (h) Stamp placed over teflon sheet and cured (i) Final restoration after finishing and polishing

\section{Discussion}

The restoration of actual topography of tooth surfaces will definitely promote patient's compliance and acceptance toward dental treatment. This case series describes a simple technique to obtain a good surface finish and actual anatomy of the direct posterior composite with minimal time required using the stamp technique with flowable composite ${ }^{[6]}$. It has also been reported for vertical bite reconstruction of worn out dentitions ${ }^{[3]}$. Other than composite, cost-effective materials like Pit and fissure sealants, Poly methyl metha acrylate [clear], Pattern resin, Gingival dam material, Vacuum formed template, Bite registration material can also be usedto produce stamp ${ }^{[7]}$.

To overcome the main disadvantage of polymerization shrinkage seen with composite restorations, it has to be done using incremental layer technique. Stamp is used in final layer to replicate the natural anatomy of occlusal surface. Teflon tape was placed as a barrier material. Instead of Teflon cling film can also be used. There is no need to remove the cling film as we can cure through it. It also protects composite material from being exposed to ambient light multiple times [8].

The most highlighted pro is, perhaps, the reduced overall time once skill is mastered as the post-restoration finishing time is decreased due to almost instantly desired good cusp-fossa relationship. This is a boon for the busy practitioners and helps improve their reputation amongst patients. Furthermore, the degree of porosities present in the final restoration is considerably reduced. This is due to the fact that the stamp matrix exerts pressure on the composite, thereby decreasing formation of microbubbles as well as interference of oxygen with polymerization of the final layerof composite. ${ }^{9}$ These factors have been shown to be major determinants for longterm success of composite restorations ${ }^{[10]}$. On the other hand, the massive introduction of different fluoridated agents seems to have masked i.e. undermined areas of dentin decay in absence of frank cavitation. This phenomenon has been identified as the 'fluoride bombs'and indicates the direct relationship of fluoride utilization withthe increasing resistance of the enamel surface ${ }^{[11]}$.

While the disadvantage of the technique is that it requires skill and clinical acumen in order to be correctly performed. Also the technique requires microbrush and flowable composite which are expensive. To overcome this disadvantage, expired flowable composite or transparent acrylic resin can be used [12].

\section{Conclusion}

Occlusal stamp technique is unique biomimetic direct composite restoration for posterior teeth which helps to 
restore the hidden caries with intact occlusal surface in less time, less post restoration filling adjustments and has better results as compared to manual method.

\section{References}

1. Raghu R, Srinivasan R. Optimizing tooth form with direct posterior composite restorations. J Conserv Dent 2011;14:330-6.

2. Perrin P, Zimmerli B, Jacky D, Lussi A, Helbling C, Ramseyer $\mathrm{S}$, et al. The stamp technique for direct composite rest00000oration. Schweiz Monatsschr Zahnmed. 2013;123:111-29.

3. Ramseyer ST, Helbling C, Lussi A. Posterior vertical bite reconstructions of erosively worn dentitions and the "stamp technique"-A case series with a mean observation time of 40 months. J Adhes Dent 2015;17:283-9.

4. Dimashkieh RM. Composite Resin Stamping Technique using a Translucent Hot Melt Adhesive. International Journal of Prosthodontics and Restorative Dentistry 2015;5:63-7.

5. Pompeu JG, Morais RC, Ferreira TO, Prado VL, Sampaio TJ, Pedrosa MS, et al. Occlusal Stamp Technique For Direct Resin Composite Restoration: A Clinical Case Report. Int J Recent Sci Res 2016;7:1242730 .

6. Alshehadat SA, Halim MS, Carmen K, Fung CS. The stamp technique for direct Class II composite restorations: A case series. J Conserv Dent 2016;19:4903.

7. Mary G, Jayadevan A. Microbrush stamp technique to achieve occlusal topography for composite resin restorations-A Technical Report. Journal of Scientific Dentistry 2016;6:76.

8. Tambake NJ, Tambake S, Gandhi N, Jadhav Y, Madhu $\mathrm{K}$, Burad $\mathrm{P}$, et al. Stamp technique-New perspective of Aesthetic Dentistry. IOSR Journal of Dental and Medical Sciences (IOSR-JDMS) 2017;16:49-51.

9. Murashkin A. Direct posterior composite restorations using stamp technique-conventional and modified: A case series. International Journal of Dentistry Research 2017;2:3-7.

10. Hamilton JC, Krestik KE, Dennison JB. Evaluation of custom occlusal matrix technique for posterior lightcured composites. Oper Dent 1998;23:303-7.

11. Martos J, Silveira LM, Ferrer-Luque CM, GonzálezLópez S. Restoration of posterior teeth using occlusal matrix technique. Indian J. Dent. Res 2010;21:596-99.

12. Nishad SV, Utsav Sharma. Stamp technique for posterior composite restorations-A case report. IOSR Journal of Dental and Medical Sciences (IOSR-JDMS) 2018;18:135 . 